\title{
Clinical and molecular findings in a Moroccan patient with popliteal pterygium syndrome: a case report
}

Ilham Ratbi ${ }^{1,4^{*}}$, Nawfal Fejjal ${ }^{2}$, Marie Legendre ${ }^{3}$, Nathalie Collot ${ }^{3}$, Serge Amselem ${ }^{3}$ and Abdelaziz Sefiani ${ }^{1,4}$

\begin{abstract}
Introduction: Popliteal pterygium syndrome is a congenital malformation that includes orofacial, musculoskeletal and genitourinary anomalies. It is a rare autosomal dominant disorder due to a mutation of the IRF6 gene on $1 \mathrm{q} 32.2$.

Case presentation: A one-month-old Moroccan baby boy was diagnosed with typical features of popliteal pterygium syndrome and carried the c.250C >T; p.Arg84Cys mutation of the IRF6 gene.

Conclusions: We report on the first description of a Moroccan popliteal pterygium syndrome patient. This diagnosis allowed us to provide an appropriate course of management to the patient and offer genetic counseling to his family.
\end{abstract}

Keywords: Popliteal pterygium syndrome, Autosomal dominant, IRF6 gene

\section{Introduction}

Popliteal pterygium syndrome (PPS, OMIM:19500) is a rare autosomal dominant malformative disorder, characterized by orofacial, cutaneous, musculoskeletal, and genital anomalies [1]. There is considerable phenotypic variability within and between families [2]. An autosomal recessive form of PPS, described as lethal-type popliteal pterygium syndrome (LPPS, MIM 263650) and also known as Bartsocas-Papas syndrome, is also described [3]. The incidence of PPS is approximately 1 in 300,000 live births [4]. Major anomalies in PPS are cleft lip and/or palate, lower lip pits or sinuses, popliteal webbing, syndactylies, and a distinctive nail anomaly comprising a pyramidal skin fold extending from the base to the top of the nails $[1,4]$. Male patients may have bifid scrotum and cryptorchidism; hypoplastic labia majora are observed in females. Other clinical findings include oral adhesions, syngnathia, ankyloblepharon, talipes, spina bifida occulta, bifid ribs, and short

\footnotetext{
* Correspondence: i.ratbi@um5s.net.ma

'Centre de génomique humaine, Faculté de médecine et pharmacie, Université Mohammed V Souissi, Angle Avenue Allal El Fassi et Mfadel Cherkaoui, 10100 Rabat, Morocco

${ }^{4}$ Département de Génétique médicale, Institut National d'Hygiène, 27, Avenue Ibn Batouta, 11400 Rabat, Morocco

Full list of author information is available at the end of the article
}

sternum. There is no growth delay and intelligence is usually normal [1]. The interferon regulatory factor- 6 gene (IRF6) on 1q32.2 was identified by Kondo et al. as responsible for both PPS and Van der Woude syndrome (VWS), a more common oral cleft syndrome (VWS, MIM 119300) [5].

We report on the first description of a Moroccan patient with popliteal pterygium syndrome carrying a missense mutation of the hotspot arginine 84 .

\section{Case presentation}

A one-month-old Moroccan baby boy was referred to our institute for a medical genetic consultation with a chief complaint of malformations diagnosed as popliteal pterygium syndrome. He was the fourth liveborn child of a healthy nonconsanguineous couple, aged 35 for the mother and 49 for the father, with no particular familial history. On clinical examination, both the parents and other siblings were normal. During pregnancy, the mother had no history of drug ingestion, abdominal trauma, or radiographic examination. The pregnancy was not medically followed, but it was reported without complications. The baby was born at term by vaginal delivery. His Apgar score was good. At birth, he weighed 3,500g; his length was $52 \mathrm{~cm}$; his head circumference was $36 \mathrm{~cm}$. On general 


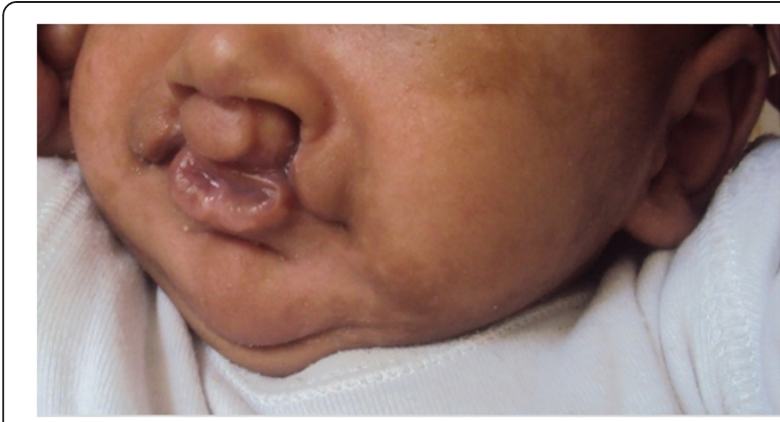

Figure 1 Index case showing a bilateral cleft lip with two large pits on his lower lip and achromic spots in his face.

physical examination, our patient had a bilateral cleft lip and palate with two large pits on the lower lip and oral synechias that did not restrict feeding (Figure 1). He presented several achromic spots of different shapes and sizes on his face. They were irregular but with a well-defined border. On Wood lamp examination, they appeared offwhite. There was an asymmetrical large-size pigmented nevus on the sole of his right foot, without relevant nails anomalies (Figures 1 and 2). He also had right popliteal pterygium and bilateral syndactyly of four to five toes (Figure 3). The urogenital examination showed a phimosis. X-rays of the skull, transfontanellar, abdominogenitourinary and cardiac ultrasonography were normal. The results of all laboratory examinations were within normal limits. Informed consent was obtained from the proband's parents prior to molecular analysis. Peripheral blood was collected from the affected child and his parents. Molecular genetic testing for suspected PPS was performed by Sanger sequencing of the entire coding region and flanking introns of the IRF6 gene (NM_006147.3). This led to the identification of the heterozygous c.250C>T;

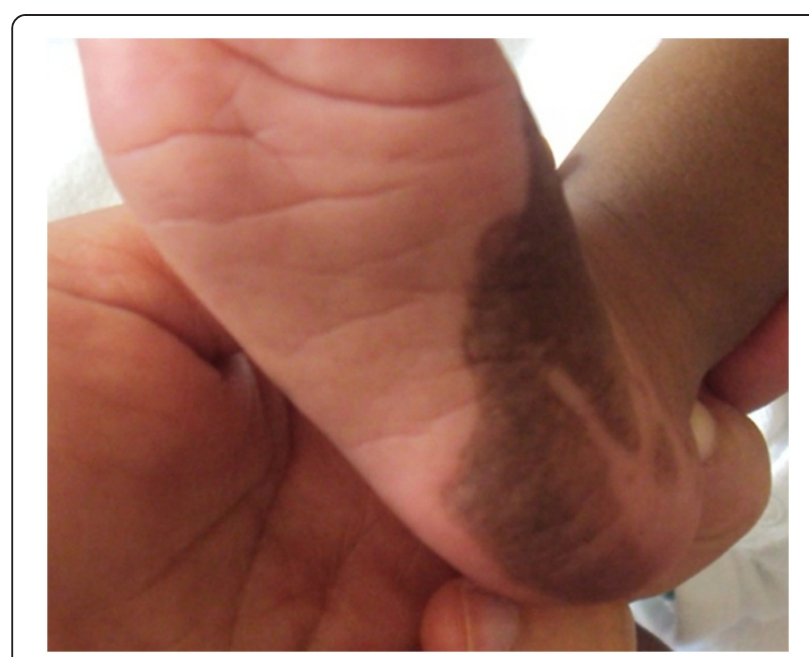

Figure 2 Verrucous hamartoma on the sole of our patient's feet.

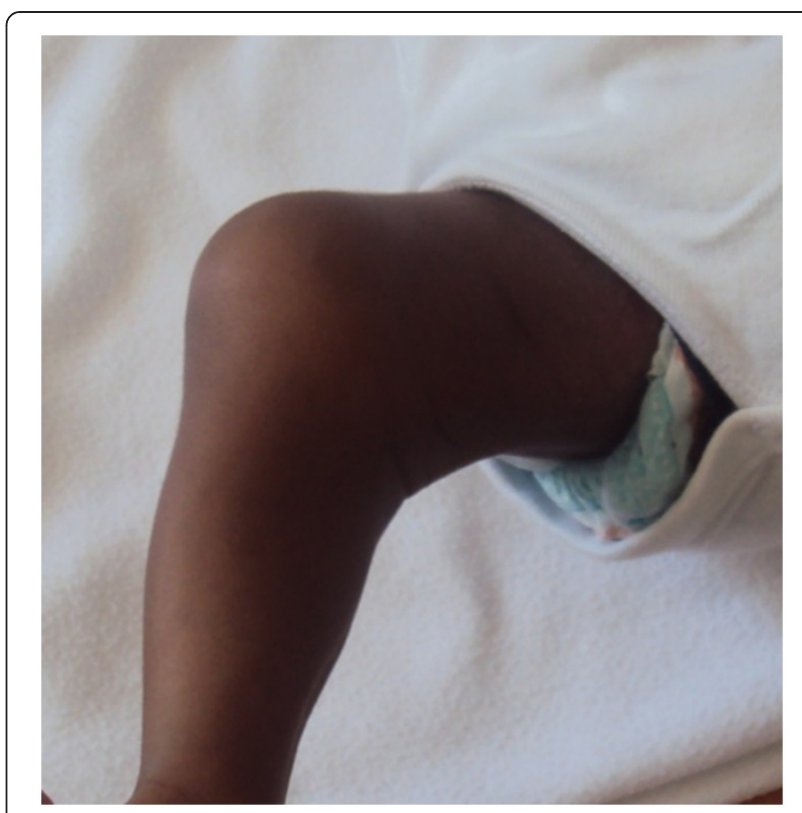

Figure 3 Right popliteal pterygium.

p.Arg84Cys mutation in exon 4 (Figure 4). This mutation occurred de novo, as it was not revealed in the hematologic cells of the parents.

Our patient was scheduled for reconstructive surgery of his cleft lip and palate, oral synechiae and popliteal pterygium.

\section{Discussion}

Popliteal pterygium syndrome (PPS) is an oral cleft syndrome with additional clinical features including webbed skin of the legs, genital hypoplasia and/or oral synechiae [1]. PPS and VWS are allelic caused by mutations of the IRF6 gene on 1q32.2 [2]. It encodes a transcription factor

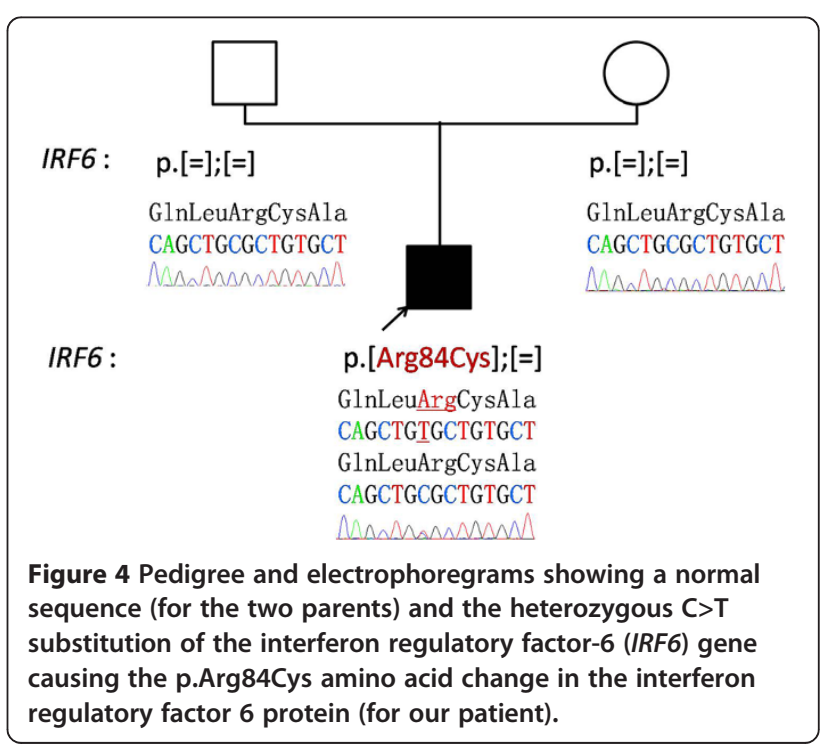


containing a helix-loop-helix (HLH) domain for DNA binding and a Smad interferon regulatory factor-binding domain (SMIR) for protein binding. IRF6 is involved in epithelial differentiation as a component of a regulatory feedback loop that controls the proliferative potential of epidermal cells [6]. The patient described here presented cutaneous lesions. IRF6 is also a potential tumor suppressor gene in squamous cell carcinomas acting on a gene network that contributes to the regulation of cancer cell invasiveness and proliferation [6]. IRF6 missense mutations are found almost exclusively in the HLH DNAbinding domain or the protein-binding/SMIR domain $[2,7]$. Amino acids that are mutated in PPS are essential for the DNA binding in particular the arginine at position 84 , which is the only one able to constitute a hydrogen bond with the guanine of the target DNA sequence. Two major dominant negative mutations p.Arg84Cys and p. Arg84His are frequently reported for PPS $[3,8]$. In the patient described here, we screened first for PPS because of the typical facial features and the pterygium poplitea. He was heterozygous for a de novo p.Arg84Cys mutation, previously reported in patients with PPS and considered deleterious $[5,7,9]$. It was also reported in a patient with VWS and in an asymptomatic individual, supporting the variability in the clinical expression and the incomplete penetrance of the disease phenotype in this syndrome [8].

\section{Conclusions}

In conclusion, we report on the first clinical and molecular description of a Moroccan patient with PPS syndrome. This diagnosis allowed us to provide an appropriate course of management to the patient, and offer genetic counseling to his family.

\section{Consent}

Written informed consent was obtained from the patient's legal guardian(s) for publication of this case report and any accompanying images. A copy of the written consent is available for review by the Editor-in-Chief of this journal.

\footnotetext{
Abbreviations

HLH: helix-loop-helix; IRF6: interferon regulatory factor 6; LPPS: lethal-type popliteal pterygium syndrome; PPS: pterygium popliteal syndrome; SMIR: Smad interferon regulatory factor-binding domain; WWS: Van der Woude syndrome.
}

\section{Competing interests}

The authors declare that they have no competing interests.

\section{Authors' contributions}

IR carried out the clinical examination of the patient and participated in the redaction of the manuscript. NF contributed to the clinical diagnosis and carried out the management of the patient. ML validated the molecular analysis and helped in the redaction of the manuscript. NC performed the molecular analysis. AS contributed to the clinical diagnosis and performed the genetic counseling. SA helped in the validation of the molecular analysis and corrected the manuscript. All authors read and approved the final manuscript.

\section{Acknowledgements}

We thank the patient and his family.

\section{Author details}

${ }^{1}$ Centre de génomique humaine, Faculté de médecine et pharmacie, Université Mohammed V Souissi, Angle Avenue Allal El Fassi et Mfadel Cherkaoui, 10100 Rabat, Morocco. ${ }^{2}$ Service de chirurgie plastique pédiatrique, Hôpital des Enfants, Boulevard Ibn Rochd, 10100 Rabat, Morocco. ${ }^{3}$ U.F. de Génétique moléculaire, Hôpital Trousseau, APHP, 26, Avenue du Docteur Arnold-Netter, 75012 Paris, France. ${ }^{4}$ Département de Génétique médicale, Institut National d'Hygiène, 27, Avenue Ibn Batouta, 11400 Rabat, Morocco.

Received: 5 September 2014 Accepted: 30 November 2014

Published: 29 December 2014

\section{References}

1. Gorlin RJ, Sedano HO, Cervenka J: Popliteal pterygium syndrome. A syndrome comprising cleft lip palate, popliteal and intercrural pterygia, digital and genital anomalies. Pediatrics 1968, 41:503-509.

2. Leslie EJ, Mancuso JL, Schutte BC, Cooper ME, Durda KM, L'heureux J, Zucchero TM, Marazita ML, Murray JC: Search for genetic modifiers of IRF6 and genotype-phenotype correlations in Van der Woude and popliteal pterygium syndromes. Am J Med Genet A 2013, 161:2535-2544.

3. Bartsocas CS, Papas CV: Popliteal pterygium syndrome. Evidence for a severe autosomal recessive form. J Med Genet 1972, 9:222-226.

4. Froster-Iskenius UG: Polpliteal pterygium syndrome. J Med Genet 1990, 27:320-326.

5. Kondo S, Schutte BC, Richardson RJ, Bjork BC, Knight AS, Watanabe $Y$, Howard E, de Lima RL, Daack-Hirsch S, Sander A, McDonald-McGinn DM, Zackai EH, Lammer EJ, Aylsworth AS, Ardinger HH, Lidral AC, Pober BR, Moreno L, Arcos-Burgos M, Valencia C, Houdayer C, Bahuau M, MorettiFerreira D, Richieri-Costa A, Dixon MJ, Murray JC: Mutations in IRF6 cause Van der Woude and popliteal pterygium syndromes. Nat Genet 2002, 32:285-289.

6. Botti E, Spallone G, Moretti F, Marinari B, Pinetti V, Galanti S, De Meo PD, De Nicola F, Ganci F, Castrignanò T, Pesole G, Chimenti S, Guerrini L, Fanciulli M, Blandino G, Karin M, Costanzo A: Developmental factor IRF6 exhibits tumor suppressor activity in squamous cell carcinomas. Proc Natl Acad Sci U S A 2011, 108:13710-13715.

7. Peyrard-Janvid M, Pegelow M, Koillinen H, Larsson C, Fransson I, Rautio J, Hukki J, Larson O, Karsten AL, Kere J: Novel and de novo mutations of the IRF6 gene detected in patients with Van der Woude or popliteal pterygium syndrome. Eur J Hum Genet 2005, 13:1261-1267.

8. Matsuzawa N, Yoshiura K, Machida J, Nakamura T, Niimi T, Furukawa H, Toyoda T, Natsume N, Shimozato K, Niikawa N: Two missense mutations in the IRF6 gene in two Japanese families with Van der Woude syndrome. Oral Surg Oral Med Oral Pathol Oral Radiol Endod 2004, 98:414-417.

9. de Lima RL, Hoper SA, Ghassibe M, Cooper ME, Rorick NK, Kondo S, Katz L, Marazita ML, Compton J, Bale S, Hehr U, Dixon MJ, Daack-Hirsch S, Boute O, Bayet B, Revencu N, Verellen-Dumoulin C, Vikkula M, Richieri-Costa A, Moretti-Ferreira D, Murray JC, Schutte BC: Prevalence and nonrandom distribution of exonic mutations in interferon regulatory factor 6 in 307 families with Van der Woude syndrome and 37 families with popliteal pterygium syndrome. Genet Med 2009, 11:241-247.

doi:10.1186/1752-1947-8-471

Cite this article as: Ratbi et al:: Clinical and molecular findings in a Moroccan patient with popliteal pterygium syndrome: a case report. Journal of Medical Case Reports 2014 8:471. 